\title{
The History and Future of Plastic and Reconstructive Surgery
}

\author{
Yong Bae Kim
}

Department of Plastic and Reconstructive Surgery, Soonchunhyang University College of Medicine, Bucheon, Korea

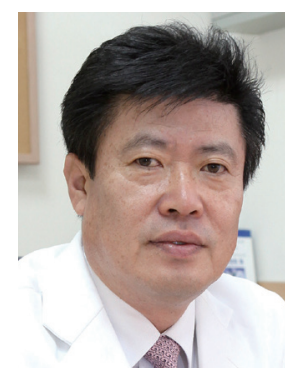

"South Korea is the plastic surgery capital of the world." This is how Korean plastic surgery was described in the Washington Post in 2015 [1]. Korea seems to be consolidating its position as a leading plastic surgery nation. However, to survive the fierce competition among plastic surgeons and to satisfy patients' highest expectations, plastic surgeons must sustain their efforts over the long term. As the old saying goes, "The past is the mirror of the future." In our case, this means that plastic surgeons can understand their current situation more clearly and prepare better for the future by understanding their past.

\section{LET'S START WITH THE STORY OF THE BEGINNING OF PLASTIC SURGERY}

It began with an effort not to leave a scar on the face while treating a cut in $4000 \mathrm{BC}$. In the eighth century, it was recorded that nose reconstruction was performed in India [2]. In the fifteenth century, Tagliacozzi, known as the father of plastic surgery, succeeded in reconstructing the nose with a forearm flap and published reports about it [2]. During many wars, including World War I, World War II, the Korean War, and the Vietnam War, modern plastic surgery emerged, as those who were injured needed reconstructive surgery, and this included techniques of wound closure, skin grafting, and flap surgery. Based on such wound healing techniques, modern plastic surgery is aiming at providing a better life for people who could have been isolated because of their deformities, such as deformities after trauma, burns, facial deformities after tumor surgery, and congenital craniofacial deformities. By providing them with aesthetic reconstruction, these patients can lead a normal life or even a better one. Furthermore, modern plastic surgery also aims at improving the quality of life in general as it develops.

\section{LET'S TAKE A LOOKAT HOW PLASTIC SURGERY WAS INTRODUCED AND HAS DEVELOPED IN KOREA}

There were two main groups of plastic surgeons who introduced plastic surgery to Korea: those who were influenced by Dr. JaeDuk Lew and those who were not. Dr. Jae-Duk Lew, who had completed his plastic surgery training in the United States in 1961 and returned to Yonsei University Medical School, was the first to introduce plastic surgery to Korea. He contributed to founding the Korean Society of Plastic and Reconstructive Surgeons (KSPRS) in 1966, and to establishing resident training programs for plastic surgery in 1973. The first board test for plastic surgeons was carried out in 1975 . KSPRS started publishing plastic surgery textbooks in 1980. Dr. Lew had disciples who contributed to expanding the plastic surgery field in many medical schools. Dr. Dae-Hong Min founded plastic surgery at Chung-Ang University, Dr. Han-Joong Kim at Ewha Womans University, Dr. Chong-Sup Park at Soonchunhyang University, Dr. Ju-Won Bin at Catholic University, Dr. Chan-Jun Chung at Hanyang University, Dr. Sung-Soo Kim at Pusan University, and Dr. Jung-Hyun Seul at Yeungnam University. Dr. Young-Gil Kim, who had been trained under Chong-Sup Park, founded plastic surgery at Cheonnam National University. The other group of plastic surgeons who were not directly influenced by Dr. JaeDuk Lew were Dr. Chin-Whan Kim, Dr. Jin-Sung Kang, Dr. 
Sung-Chun Choi, and Dr. Bong-Su Baik. Dr. Chin-Whan Kim, who had completed his training at New York University under Dr. J.M. Converse's supervision, founded plastic surgery at Seoul National University. He first introduced craniofacial anomaly operations and the face lift to Korea. Dr. Jin-Sung Kang, who had finished his training at King's County Medical Center, founded plastic surgery at Keimyung University and wrote the textbook entitled Plastic Surgery. Dr. Sung-Chun Choi trained at Metropolitan Hospital in Japan and founded plastic surgery at KyungHee University, while Dr. Bong Soo Baik founded it at Kyungpook University.

After being introduced by these two groups, plastic surgery has been greatly developed by many plastic surgeons in Korea. Notably Dr. Se-Min Baek, who had practiced at Mount Sinai Hospital in the United States, made the biggest contribution to establishing craniofacial reconstructive surgery in Korea by performing two jaw surgeries and craniofacial plastic surgery for the first time in Korea.

Although Korean plastic surgery started and developed through the influence of other countries, Korea is now the most influential country in plastic surgery worldwide. As Korea's economy dramatically grew by achieving "the miracle on the Han River" in the 1960's and 70's, the field of plastic surgery greatly advanced its knowledge and skills in Korea at the same time. To be specific, KSPRS was established in 1966 and more than 2000 plastic surgeons have since been trained in Korea. Furthermore, the Korean Conference of Plastic Surgery, held every year, has internationalized, allowing surgeons from all over the world to participate. The field has also made great strides in clinical research, as proven by the large number of articles Korean plastic surgeons submit successfully to high-level plastic surgery journals with Science Citation Index status. Just as the Korean Wave is spreading Korean television dramas, K-pop music, and fashion worldwide, Koreans are leading the world in plastic surgery.

However, these rapid developments of Korean plastic surgery are causing some unexpected problems: an imbalance between reconstructive surgery and aesthetic surgery, a distorted perspec- tive on aesthetic surgery, and ambiguity of scholarship in plastic surgery. To address these problems, we, today's plastic surgeons, must keep in mind how plastic surgery originated in Korea by looking back on our past. This is not the same as just sticking to the past. While we retain our focus on wound healing and tissue reconstruction, we must apply more advanced technology and skills to these goals, including tissue engineering, gene therapy, robotic surgery, 3-dimensional printing technology, and the development of new biocompatible materials. When we generate more interest and investment in these areas, we can build a new growth engine for the development of Korean plastic surgery and build a sustainable model of development.

I would like to express my sincere appreciation for the efforts of many senior teachers who have contributed to developing Korean plastic surgery. Likewise, I support the efforts of young teachers who are leading us into the future of Korean plastic surgery. I hope that all of you have a promising future and limitless possibilities.

\section{REFERENCES}

1. Swanson A. Wonkblog: Stunning photos show why S. Korea is the plastic surgery capital of the world [Internet]. Washington, DC: The Washington Post; c2015 [cited 2015 May 16]. Available from: http://www.washingtonpost.com/news/ wonkblog/wp/2015/05/16/stunning-photos-show-whysouth-korea-is-the-plastic-surgery-capital-of-the-world/.

2. Neligan PC. Plastic surgery. 3rd ed. St. Louis, MO: Elsevier Saunders; 2012.

\section{Correspondence: Yong Bae Kim}

Department of Plastic and Reconstructive Surgery, Soonchunhyang University Bucheon Hospital, Soonchunhyang University College of Medicine, 170 Jomaruro, Wonmi-gu, Bucheon 14584, Korea Tel: +82-32-621-5312, Fax: +82-32-621-5316, E-mail: psybkim@naver.com

No potential conflict of interest relevant to this article was reported.

Received: 12 Aug 2015 • Revised: 13 Aug 2015• Accepted: 14 Aug 2015 pISSN: 2234-6163・ elSSN: 2234-6171

http://dx.doi.org/10.5999/aps.2015.42.5.515 • Arch Plast Surg 2015;42:515-516 